\title{
Rigorous or practical? A new approach to develop rate laws for mineral dissolution
}

\author{
INNA KURGANSKAYA AND ANDREAS LUTTGE
}

University of Bremen

Presenting Author: inna.kurganskaya@uni-bremen.de

Quantification of dissolution reaction rates is of great importance for practical purposes, such as an estimation of material fluxes and concentrations of various ions or molecules in diverse geochemical environments. The existing theoretical rate laws provide quantitative relationships between mineral phases and the chemical composition of fluids[1]. The current formulation of rate laws has some conceptual issues widely discussed during the last decade[2]. A cornerstone issue is the prediction of intrinsic rates or rate constants that appear in kinetic equations relating the concentrations of ions in the fluids and dissolution rates in units of material flux. This issue is essentially related to the variance of reactive sites on the crystal surfaces $[3,4]$, which is not covered by the rate laws available in the literature. We present here an alternative approach to derive rate equations that are based on statistical mechanics of dissolution and precipitation reactions at mineral surfaces. Further, we show how the new rate law is applied to calcite $\left(\mathrm{CaCO}_{3}\right)$ and explains the variance in measured dissolution rates. We use complementary $\mathrm{KMC}$ simulations [5] to illustrate different reaction pathways to equilibrium when the rate is treated as a function of the difference of Gibbs free energy. We also show how this new rate equation can be used to explain inconsistencies in rate saturation state dependence measured in experiments. A common argument for the use of classical empirically parameterized rate equations is their practical applicability. We argue that a more rigorous approach that resembles the physical reality can be used[6].

[1] Lasaga (1998) Kinetic Theory in the Earth Sciences, Princeton University Press

[2] Lüttge, Arvidson \&Fischer (2013) ELEMENTS, 183-8.

[3] Arvidson, Ertan, Amonette \& Luttge (2003) Geochim. Cosmochim. Acta, 1623-34.

[4] Fischer, Arvidson \& Lüttge (2012) Geochim. Cosmochim. Acta, 177-85.

[5] Kurganskaya \& Luttge (2016) J. Phys. Chem. C, 6482-92.

[6] Kurganskaya \& Luttge (2021) submitted 